\section{Effect of psychological stress on blood pressure increase: a meta-analysis of cohort studies}

\author{
Efeito do estresse psicológico no aumento \\ da pressão arterial: uma metanálise \\ de estudos de coorte
}

\author{
1 Programa de Pós-gradu- \\ ação em Saúde Coletiva, \\ Universidade do Vale do Rio \\ dos Sinos, São Leopoldo, \\ Brasil. \\ 2 Department of Primary \\ Care and Social Medicine, \\ Imperial College, \\ London, UK. \\ 3 Faculdade de Medicina, \\ Universidade Federal de \\ Pelotas, Pelotas, Brasil. \\ Correspondence \\ M. P. Pattussi \\ Programa de Pós-graduação \\ em Saúde Coletiva, \\ Universidade do Vale do \\ Rio dos Sinos. \\ Av. Unisinos 950, C. P. 275 \\ São Leopoldo, RS \\ 93022-000, Brasil. \\ mppattussi@unisinos.br
}

\begin{abstract}
Studies have suggested that chronic exposure to stress may have an influence on increased blood pressure. A systematic review followed by a meta-analysis was conducted aiming to assess the effect of psychological stress on blood pressure increase. Research was mainly conducted in Ingenta, Psycinfo, PubMed, Scopus and Web of Science. Inclusion criteria were: published in any language; from January 1970 to December 2006; prospective cohort design; adults; main exposure psychological/emotional stress; outcome arterial hypertension or blood pressure increase $\geq 3.5 \mathrm{mmHg}$. A total of 2,043 studies were found, of which 110 were cohort studies. Of these, six were eligible and yielded 23 comparison groups and 34,556 subjects. Median follow-up time and loss to follow-up were 11.5 years and $21 \%$. Results showed individuals who had stronger responses to stressor tasks were $21 \%$ more likely to develop blood pressure increase when compared to those with less strong responses (OR: 1.21; 95\%CI: 1.141.28; $p<0.001)$. Although the magnitude of effect was relatively small, results suggest the relevance of the control of psychological stress to the nontherapeutic management of high blood pressure.
\end{abstract}

Blood Pressure; Hypertension; Psychological Stress

\author{
Daniela Gasperin 1 \\ Gopalakrishnan Netuveli 2 \\ Juvenal Soares Dias-da-Costa 1,3 \\ Marcos Pascoal Pattussi 1
}

\section{Introduction}

According to the World Health Organization 1, non-transmissible diseases will be the leading cause of functional disability in the next two decades and, among chronic degenerative conditions, arterial hypertension will be the most important cause. Hypertension is a public health concern due to its magnitude, risks, difficulty in management, high medical and social costs and severe cardiovascular and renal complications 2 . The number of deaths due to hypertension as primary cause was estimated to be over 7 million in 2002 , approximately $13 \%$ of all reported deaths 1 . Hypertensive adults will reach 1.5 billion by 2025 , around $30 \%$ of the world population 3 .

Hypertension management comprises drug and/or non-drug therapeutic approaches. Although there is clear evidence that antihypertensive medications are useful in controlling hypertension and reducing the incidence of stroke and infarction 2, long-term drug treatment can be expensive and side-effects can threaten patients' adherence to drug prescriptions ${ }^{4}$. The identification of non-pharmacological methods to prevent, or significantly delay the onset of hypertension would represent an important advance in the prevention of cardiovascular disease 2. Among non-drug approaches, lifestyle changes recommended include: weight reduction, a diet rich in fruits, vegetables, and low fat dairy products with a reduced content of satu- 
rated and total fat, dietary sodium reduction, engagement in regular aerobic physical activity and limited alcohol consumption ${ }^{2}$. Extensive trials of over 100 randomized trials indicates the efficacy of behavioral treatments for hypertension ${ }^{5}$. Behavioral changes should also include anti-stress activities 6 .

The Medical Subject Headings (MeSH) defines stress as a pathological process resulting from body response to external forces and abnormal states that tend to affect its homeostasis. It comprises daily events that increase physiological activities and consequently cause psychological wear and tear to some extent 7 . When emotional stressors are prevailing, this condition is known as psychological stress. Modern life events such as work-related and family problems, social withdrawal, financial worries and violence are some factors that can predispose or potentate stress ${ }^{8}$.

It has been suggested that chronic exposure to psychological stress can cause increased blood pressure and lead to hypertension development 5 . A cohort study of over 3,000 young adults 9 showed that urgency/impatience behavior, and hostility assessed during young adulthood were strongly associated with a higher risk of developing hypertension 15 years later. Other exposures such as depression and anxiety were also reported. Chronic stress due to financial strain has been reported to predict high blood pressure during three to seven years of follow-up 10. A study with 11,119 cases and 13,648 controls from 52 countries 11 reported strong associations of myocardial infarction (cases) and more frequent periods of stress at home, more severe financial stress and more stressful life events compared with controls. In terms of myocardial infarction risk, the effect of psychosocial stress was as important in magnitude as traditional cardiovascular disease risk factors such as smoking, obesity, diabetes and hypertension. In addition, a systematic review of 23 treatment comparisons from 17 randomized trials conducted in patients with elevated blood pressure, demonstrated strong effects of transcendental meditations on reductions in blood pressure. Despite non-significant results, other anti-stress interventions such as biofeedback, progressive muscle relaxation and stress management training also reported clinically important reductions in blood pressure 12 . Therapies such as these may help patients to reduce the effects of stress by reducing physiologic arousal and restoring autonomic balance, thereby reducing blood pressure 5 .

The purpose of the present meta-analysis was to assess the effect of psychological stress on blood pressure increase.

\section{Methods}

A systematic review followed by meta-analysis of prospective cohort studies was conducted.

\section{Search strategy}

The systematic search of articles was carried out based on Undertaking Systematic Reviews of Research on Effectiveness guidelines 13 and Cochrane Reviewers' Handbook 14. The following databases were searched: Biological Abstracts; CAB Abstracts; Ingenta; Psycinfo; PubMed; Scopus; Web of Science; SIGLE; NTIS; NDLTD and reference lists of the selected articles. Table 1 shows searches in the different databases.

\section{Inclusion and exclusion criteria}

Inclusion criteria were: published between January 1970 and December 2006, with this starting date chosen because studies investigating the effect of psychological stress on the development of morbid conditions were first published in that decade 15,16; prospective cohort design, this study design being one of the most appropriate for assessing causality 17 while taking into consideration the major issue of temporality, i.e., exposure prior to disease; 18 to 64 year-old normotensive adults; main exposure measured through reactivity or recovery, reactivity is the difference between blood pressure during the stressor task and baseline 18 and recovery is blood pressure measured after a stressful task 19 ; dichotomous outcome as arterial hypertension or increase in systolic and/or diastolic blood pressure $\geq 3.5 \mathrm{mmHg}$; and reporting relative risks, hazard ratios or odds ratios (OR).

Articles were excluded if they were based on hypertensive men and/or women at enrollment; reported other types of stress or if outcome was measured on a continuous scale.

\section{Study quality}

The quality of studies selected for inclusion in the meta-analysis was assessed. Assessments were based on the National Institute for Health and Clinical Excellence criteria 20 including subject selection, refusals, losses to follow-up, exposure and outcome measurement, level of exposure and adjustments for confounders. Two independent evaluators conducted quality assessments.

\section{Data extraction}

Data were independently extracted by two researchers. The principal information obtained 
Searches, keywords and boolean operators, number of retrieved and selected articles according to the databases.

\begin{tabular}{|c|c|c|c|c|}
\hline $\begin{array}{l}\text { Date of } \\
\text { search }\end{array}$ & Database & Keywords & $\begin{array}{c}\text { Retrieved } \\
\text { articles }\end{array}$ & $\begin{array}{c}\text { Selected } \\
\text { articles }\end{array}$ \\
\hline 03/Jan/2007 & $\begin{array}{c}\text { Biological } \\
\text { Abstracts, CAB } \\
\text { Abstracts and } \\
\text { Psycinfo }\end{array}$ & $\begin{array}{l}\text { (stress OR psychological stress OR emotional stress OR life stress) } \\
\text { AND (blood pressure OR hypertension) AND } \\
\text { (cohort studies OR prospective studies OR follow-up studies) }\end{array}$ & 34 & 0 \\
\hline 04/Jan/2007 & Ingenta & $\begin{array}{l}\text { (stress OR psychological stress OR emotional stress OR life stress) AND } \\
\text { (blood pressure OR hypertension) AND } \\
\text { (cohort studies OR prospective studies OR follow-up studies) }\end{array}$ & 62 & 0 \\
\hline 08/Jan/2007 & PubMed & $\begin{array}{l}\text { (stress [MeSH] OR psychological stress [mh] OR emotional stress [mh] OR life stress } \\
\text { [mh]) AND (hypertension [MeSH] OR blood pressure [MeSH]) AND } \\
\text { ((cohort studies [MeSH] OR risk [MeSH] OR (odds [WORD] AND ratio* } \\
\text { [WORD]) OR (relative [WORD] AND risk [WORD])). } \\
\text { Limits: Adolescent: 13-18 years, Adult: 19-44 years, Middle Aged: 45-64 years, } \\
\text { Publication Date from 1970/01/01 to 2006/12/31, Journal Article, Humans.years, } \\
\text { Middle Aged: } 45-64 \text { years, Publication Date from 1970/01/01 to } \\
\text { 2006/12/31, Journal Article, Humans }\end{array}$ & 617 & 5 \\
\hline 09/Jan/2007 & Scopus & $\begin{array}{c}\text { (stress OR psychological stress OR emotional stress OR life stress) AND } \\
\text { (hypertension OR blood pressure) AND (cohort studies } \\
\text { OR prospective studies OR follow-up studies) }\end{array}$ & 13 & 0 \\
\hline 09/Jan/2007 & Web of Science & $\begin{array}{c}\text { (stress OR psychological stress OR emotional stress OR life stress) AND } \\
\text { (hypertension OR blood pressure) AND (cohort studies } \\
\text { OR prospective studies OR follow-up studies) }\end{array}$ & 1,158 & 5 \\
\hline 10/Jan/2007 & NITS & $\begin{array}{c}\text { (stress OR psychological stress OR emotional stress OR life stress) AND } \\
\text { (hypertension OR blood pressure) AND (cohort studies } \\
\text { OR prospective studies OR follow-up studies) }\end{array}$ & 0 & 0 \\
\hline 10/Jan/2007 & SIGLE & $\begin{array}{c}\text { (stress OR psychological stress OR emotional stress I OR life stress) } \\
\text { AND (hypertension OR blood pressure) AND (cohort studies } \\
\text { OR prospective studies OR follow-up studies) }\end{array}$ & 0 & 0 \\
\hline 10/Jan/2007 & NDLTD & $\begin{array}{c}\text { (stress OR psychological stress OR emotional stress OR life stress) } \\
\text { AND (hypertension OR blood pressure) AND (cohort studies } \\
\text { OR prospective studies OR follow-up studies) }\end{array}$ & 160 & 0 \\
\hline
\end{tabular}

included: title, authors, journal, year of publication, country, number of subjects, follow-up time, losses to follow-up, age, study population, measurement of exposure, outcome and confounders in the multivariable model.

Most studies reported OR as the measure of effect. Data extracted from each article were neperian logarithm of OR and standard error (SE). One study reported the hazard ratio 21 and another reported the relative risk 22 and these measures were converted into OR 23 . When only confidence intervals were available, they were converted into SE 14 .

\section{Data analysis}

Data analyses were performed using Stata software 9.2 (Stata Corp., College Station, USA). The variability of the selected studies was evaluated through a heterogeneity test using models with 
fixed effects when the test was statistically nonsignificant $(p \geq 0.05)$ and random effects when the test was statistically significant $(p<0.05) 14$. Begg's and Egger's tests were used to investigate the existence of publication bias 24 .

To avoid potential effects of heterogeneity and assess the individual impact of each variable studied, analyses were conducted by the following subgroups: age, gender, study losses, years of follow-up, test applied, exposure measurement and multivariable analysis. Lastly, a combination of measures of effect by study was assessed as well as the impact of exclusion of each study on the combined effect.

\section{Results}

Figure 1 shows the number of studies found and reasons for exclusion at each step of the systematic search. Of 110 cohort studies, six were selected yielding 23 comparison groups. For example, Steptoe et al. 25 assessed the effect of middle and highest tercile systolic and diastolic blood pressure recovery on two outcomes: increased blood pressure $\geq 3.5 \mathrm{mmHg}$ and $\geq 5 \mathrm{mmHg}$, thus providing 8 comparisons (2x2x2). Table 2 illustrates the study characteristics and comparisons of the meta-analysis.

Of the cohort studies included in the metaanalysis, three were from North America and three from Europe. The sum of subjects in the comparisons yielded a total of 34,556 subjects. Mean follow-up was 11.8 years ranging between 3 to 25 years. Loss to follow-up ranged from between $8.3 \%$ and $34.2 \%$. In most studies, exposure was measured through reactivity to mental tasks. The main method of analysis was logistic regression and the main measure of effect was OR (Table 2).

The Q test showed the existence of heterogeneity among studies (Figures 2 and 3 ). Therefore results from random effect models showed that those subjects with higher reactivity/recovery were $21 \%$ more likely to have blood pressure increase when compared to those with lower reactivity/recovery (OR $=1.21$; 95\%CI: $1.14-1.28)$ (Figure 2). Similar results were found when only one measure of effect by study was considered $(\mathrm{OR}=1.28$; 95\%CI: 1.13-1.43) (Figure 3). The exclusion of the Matthews et al. 21 or Markovitz's et al. 26 studies increased the effect of psychological stress on blood pressure by about $20 \%(\mathrm{OR}=1.51$; 95\%CI: 1.17-1.94).

The subgroup analysis revealed significant effects $(\mathrm{OR}>2)$ in studies including subjects over 46 years of age, small losses to follow-up, long-term follow-up, those with a combination of stressful tasks and those where exposure was measured through recovery (Table 3). In addition, heterogeneity between studies was non-significant when the outcome was hypertension, exposure was measured by recovery, combinations of tests, females and studies with longer years of follow-up and lower losses.

\section{Publication bias}

Both Begg's and Egger's tests showed statistically significant results that were confirmed by the funnel plot asymmetry.

\section{Discussion}

The present meta-analysis assessed the effect of psychological stressful tasks on blood pressure increase in adults aged between 18 and 64 years. Individuals with high increases of blood pressure during stressful tasks (reactivity) and those with high blood pressure in the recovery period after the tasks (recovery) showed greater odds of developing hypertension or increased blood pressure. This finding corroborates other findings of studies on the association between psychological stress and blood pressure increase 27,28,29

It has been suggested that repeated episodes of heightened cardiovascular reactivity could contribute to hypertension development by promoting vascular remodeling ${ }^{30}$. These pathophysiological changes, in turn, could alter the long-term regulation of blood pressure by the kidneys, resulting in a shift in the blood pressure set point to higher levels. Poor cardiovascular recovery could contribute to hypertension development through the same mechanisms that have been proposed for heightened cardiovascular reactivity 31 . Alternatively, it has been hypothesized that both heightened cardiovascular reactivity and poor cardiovascular recovery could be markers for other pathophysiological processes involved in the etiology of hypertension, such as dysfunction in the regulation of the heart and vasculature by the autonomic nervous system ${ }^{32}$. More specifically, heightened cardiovascular reactivity could reflect sympathetic hyperresponsivity or enhanced vagal withdrawal during stress, whereas poorer cardiovascular recovery could be due to prolonged sympathetic activation, diminished vagal tone, or attenuated or delayed vagal rebound following the termination of stress 33 . In addition, several studies have reported associations between psychosocial variables and vascular function 34,35, inflammation 36 , increased blood clotting and decreased fibrinolysis 37,38 . 
Figure 1

Number of selected studies and reasons for exclusion at each step of the systematic search.

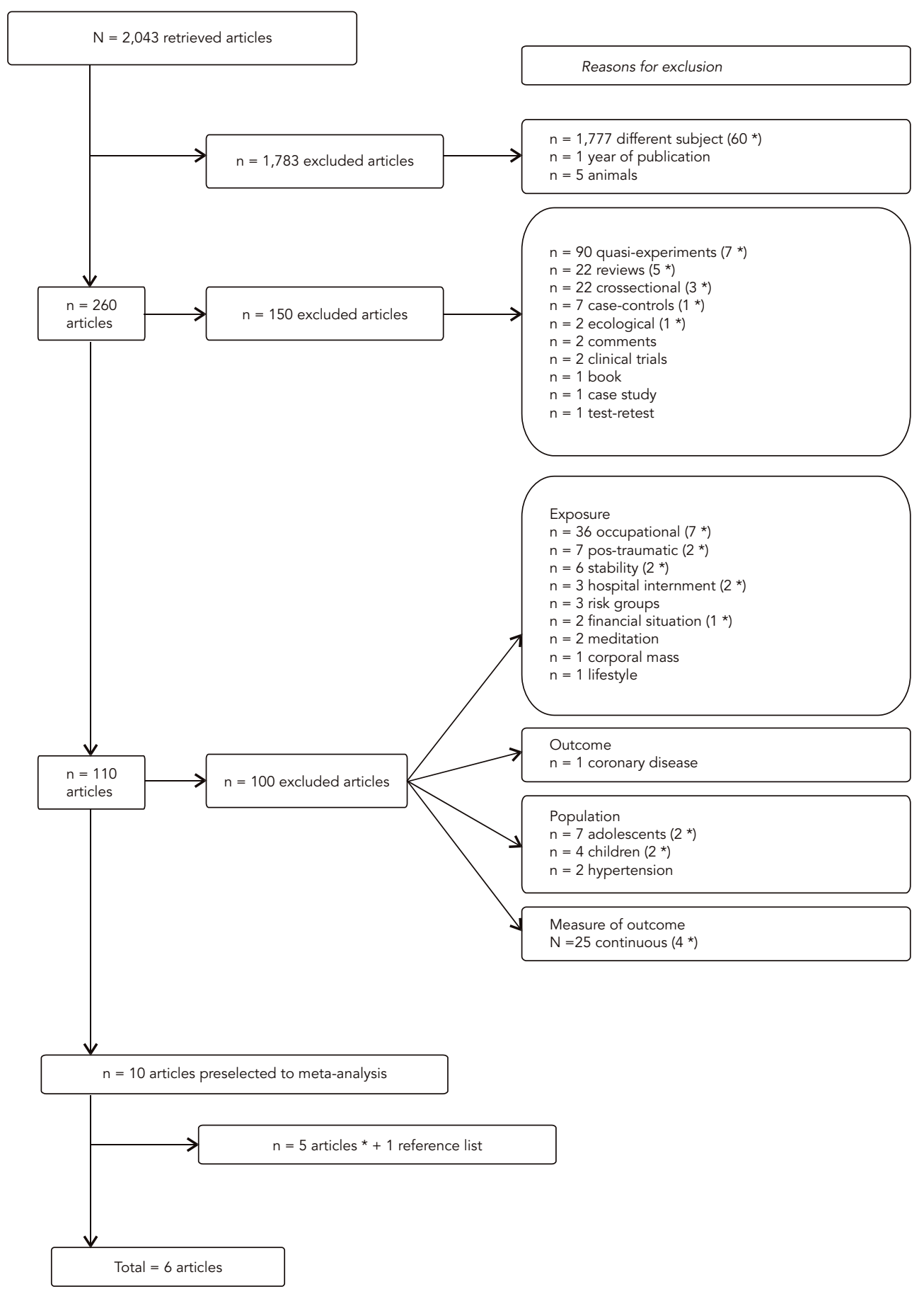

* Duplicates in different databases. 
Descriptive characteristics of studies and comparisons of the meta-analysis.

\begin{tabular}{|c|c|c|c|c|c|c|c|}
\hline Author & Country & Baseline (n) & End (n) & Loss (\%) & $\begin{array}{c}\text { Years of } \\
\text { follow-up }\end{array}$ & Age & Participants \\
\hline Borghi et al. 43 & Italy & 89 & 70 & 21.3 & 15 & $<45$ & Men/Women \\
\hline Carroll et al. a 44 & England & 1,003 & 796 & 20.6 & 10 & $35-55$ & Men \\
\hline Carroll et al. b 44 & England & 1,003 & 796 & 20.6 & 10 & $35-55$ & Men \\
\hline Markovitz et al. a 26 & USA & 5,115 & 1,557 & 34.2 & 5 & $45-59$ & Men * \\
\hline Markovitz et al. b 26 & USA & 5,115 & 1,557 & 34.2 & 5 & $45-59$ & Men * \\
\hline Markovitz et al. c 26 & USA & 5,115 & 1,763 & 34.2 & 5 & $45-59$ & Women * \\
\hline Markovitz et al. d 26 & USA & 5,115 & 1,763 & 34.2 & 5 & $45-59$ & Women * \\
\hline Matthews et al. a 21 & USA & 5,115 & 3,553 & 30.5 & 13 & $18-30$ & Men/Women \\
\hline Matthews et al. b 21 & USA & 5,115 & 4,075 & 20.3 & 13 & $18-30$ & Men/Women \\
\hline Matthews et al. c 21 & USA & 5,115 & 4,100 & 19.8 & 13 & $18-30$ & Men/Women \\
\hline Matthews et al. d 21 & USA & 5,115 & 3,463 & 32.3 & 13 & $18-30$ & Men/Women \\
\hline Matthews et al. e 21 & USA & 5,115 & 4,108 & 19.7 & 13 & $18-30$ & Men/women \\
\hline Matthews et al. f 21 & USA & 5,115 & 4,122 & 19.4 & 13 & $18-30$ & Men/Women \\
\hline Menkes et al. a 22 & USA & 1,130 & 815 & 19.3 & 25 & $<45$ * & Men \\
\hline Menkes et al. b 22 & USA & 1,130 & 346 & 19.3 & 25 & $\geq 45$ * & Men \\
\hline Steptoe et al. a 25 & England & 228 & 209 & 8.3 & 3 & $45-59$ & Men/Women \\
\hline Steptoe et al. b 25 & England & 228 & 209 & 8.3 & 3 & $45-59$ & Men/Women \\
\hline Steptoe et al. c 25 & England & 228 & 209 & 8.3 & 3 & $45-59$ & Men/Women \\
\hline Steptoe et al. d 25 & England & 228 & 209 & 8.3 & 3 & $45-59$ & Men/Women \\
\hline Steptoe_et al e 25 & England & 228 & 209 & 8.3 & 3 & $45-59$ & Men/Women \\
\hline Steptoe et al. $f 25$ & England & 228 & 209 & 8.3 & 3 & $45-59$ & Men/Women \\
\hline Steptoe et al. g 25 & England & 228 & 209 & 8.3 & 3 & $45-59$ & Men/Women \\
\hline Steptoe et al. h 25 & England & 228 & 209 & 8.3 & 3 & $45-59$ & Men/Women \\
\hline
\end{tabular}

(continues) 
Descriptive characteristics of studies and comparisons of the meta-analysis.

\begin{tabular}{|c|c|c|c|c|c|}
\hline Exposure & $\begin{array}{l}\text { Severity } \\
\text { of exposure }\end{array}$ & Stress task & $\begin{array}{l}\text { Outcome } \\
(\mathrm{mm} / \mathrm{Hg})\end{array}$ & Analysis & Confounders \\
\hline Reactivity DBP & High & Mental arithmetic & $\begin{array}{c}\text { HTN } \\
(\mathrm{DBP}>95)\end{array}$ & Logistic regression & $\begin{array}{c}\text { Age, BMI, sex, cholesterol, } \\
\text { family history of HTN, baseline SBP/DBP }\end{array}$ \\
\hline Reactivity SBP * & High & Raven's matrices & $\begin{array}{c}\mathrm{HTN} \\
(\mathrm{SBP} \geq 16 \\
\mathrm{DBP} \geq 90)\end{array}$ & Logistic regression & Age, baseline SBP \\
\hline Reactivity DBP * & High & Raven's matrices & $\begin{array}{c}\mathrm{HTN} \\
(\mathrm{SBP} \geq 160 \\
\mathrm{DBP} \geq 90)\end{array}$ & Logistic regression & Age, baseline SBP \\
\hline Reactivity SBP & Moderate * & Video game & Increase $\geq 8$ & Logistic regression & - \\
\hline Reactivity SBP & High * & Video game & Increase $\geq 8$ & Logistic regression & - \\
\hline Reactivity SBP & Moderate * & Video game & Increase $\geq 8$ & Logistic regression & - \\
\hline Reactivity SBP & High * & Video game & Increase $\geq 8$ & Logistic regression & - \\
\hline Reactivity SBP * & High & Cold pressor * & $\begin{array}{c}\mathrm{HTN} \\
(\mathrm{SBP} \geq 140 \\
\mathrm{DBP} \geq 90)\end{array}$ & Cox Regression & Age, BMI, education, SBP/DBP \\
\hline Reactivity SBP * & High & Star tracing * & $\begin{array}{c}\mathrm{HTN} \\
(\mathrm{SBP} \geq 140 \\
\mathrm{DBP} \geq 90)\end{array}$ & Cox regression & Age, BMI, education, SBP/DBP \\
\hline Reactivity SBP * & High & Vídeo game * & $\begin{array}{c}\mathrm{HTN} \\
(\mathrm{SBP} \geq 140 \\
\mathrm{DBP} \geq 90)\end{array}$ & Cox regression & Age, BMI, education, SBP/DBP \\
\hline Reactivity DBP * & High & Cold pressor * & $\begin{array}{c}\mathrm{HTN} \\
(\mathrm{SBP} \geq 140 \\
\mathrm{DBP} \geq 90)\end{array}$ & Cox regression & Age, BMI, education, SBP/DBP \\
\hline Reactivity DBP * & High & Star tracing * & $\begin{array}{c}\mathrm{HTN} \\
(\mathrm{SBP} \geq 140 \\
\mathrm{DBP} \geq 90)\end{array}$ & Cox regression & Age, BMI, education, SBP/DBP \\
\hline Reactivity DBP * & High & Vídeo game * & $\begin{array}{c}\mathrm{HTN} \\
(\mathrm{SBP} \geq 140 \\
\mathrm{DBP} \geq 90)\end{array}$ & Cox regression & Age, BMI, education, SBP/DBP \\
\hline Reactivity SBP & High & Cold pressor & Increase $\geq 20$ SBP/DBP & Cox regression & Age, BMI, smoking, HTN familial history, SBP \\
\hline Reactivity SBP & High & Cold pressor & Increase $\geq 20$ SBP/DBP & Cox regression & Age, BMI, smoking, HTN familial history, SBP \\
\hline Recovery SBP * & Moderate * & $\begin{array}{l}\text { Colour-word/ } \\
\text { Mirror tracing }\end{array}$ & Increase $\geq 5 \mathrm{SBP}$ * & Logistic regression & $\begin{array}{l}\text { Age, sex, job, antihypertensive medications, } \\
\text { BMI, smoking, baseline SBP }\end{array}$ \\
\hline Recovery SBP * & High * & $\begin{array}{l}\text { Colour-word/ } \\
\text { Mirror tracing }\end{array}$ & Increase $\geq 5 \mathrm{SBP}$ * & Logistic regression & $\begin{array}{l}\text { Age, sex, job, antihypertensive medications, } \\
\text { BMI, smoking, baseline SBP }\end{array}$ \\
\hline Recovery DBP * & Moderate * & $\begin{array}{l}\text { Colour-word/ } \\
\text { Mirror tracing }\end{array}$ & Increase $\geq 5 \mathrm{SBP}$ * & Logistic regression & $\begin{array}{l}\text { Age, sex, job, antihypertensive medications, } \\
\text { BMI, smoking, baseline SBP }\end{array}$ \\
\hline Recovery DBP * & High * & $\begin{array}{l}\text { Colour-word/ } \\
\text { Mirror tracing }\end{array}$ & Increase $\geq 5 \mathrm{SBP}$ * & Logistic regression & $\begin{array}{l}\text { Age, sex, job, antihypertensive medications, } \\
\text { BMI, smoking, baseline SBP }\end{array}$ \\
\hline Recovery SBP * & Moderate * & $\begin{array}{l}\text { Colour-word/ } \\
\text { Mirror tracing }\end{array}$ & Increase $\geq 3.5 \mathrm{DBP}$ * & Logistic regression & $\begin{array}{l}\text { Age, sex, job, antihypertensive medications, } \\
\text { BMI, smoking, baseline DBP }\end{array}$ \\
\hline Recovery SBP * & High * & $\begin{array}{l}\text { Colour-word/ } \\
\text { Mirror tracing }\end{array}$ & Increase $\geq 3.5 \mathrm{DBP}$ * & Logistic regression & $\begin{array}{l}\text { Age, sex, job, antihypertensive medications, } \\
\text { BMI, smoking, baseline DBP }\end{array}$ \\
\hline Recovery DBP * & Moderate * & $\begin{array}{l}\text { Colour-word/ } \\
\text { Mirror tracing }\end{array}$ & Increase $\geq 3.5 \mathrm{DBP}$ * & Logistic regression & $\begin{array}{l}\text { Age, sex, job, antihypertensive medications, } \\
\text { BMI, smoking, baseline DBP }\end{array}$ \\
\hline Recovery DBP * & High * & $\begin{array}{l}\text { Colour-word/ } \\
\text { Mirror tracing }\end{array}$ & Increase $\geq 3.5 \mathrm{DBP}$ * & Logistic regression & $\begin{array}{l}\text { Age, sex, job, antihypertensive medications, } \\
\text { BMI, smoking, baseline DBP }\end{array}$ \\
\hline
\end{tabular}

HTN: hypertension; SBP: systolic blood pressure; DBP: dyastolic blood pressure; BMI: body mass index. Note: letters at end of authors' name shows different comparison groups within a single study.

* Indicates the location of differences between comparison groups. 
Random effect model, odds ratio for increased blood pressure $\geq 3.5 \mathrm{mmHg} /$ hipertension of the effect of responses to stressor tasks in 23 comparison groups from 6 prospective cohorts.

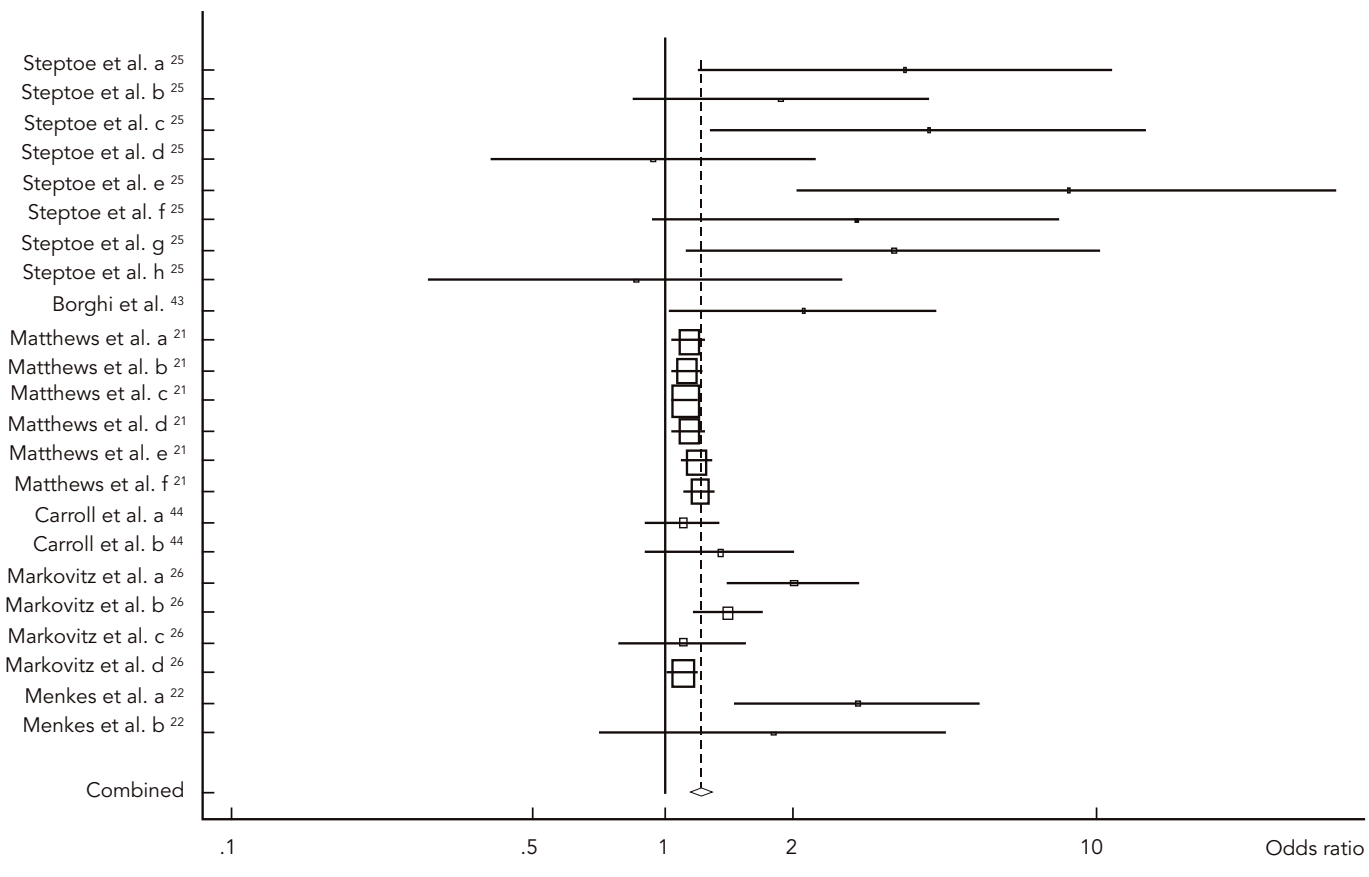

\begin{tabular}{ccc}
\multicolumn{3}{c}{ Study $(95 \% \mathrm{Cl})$} \\
OR & Lower & Upper \\
3.60 & 1.20 & 10.78 \\
1.86 & 0.85 & 4.07 \\
4.10 & 1.29 & 13.02 \\
0.94 & 0.40 & 2.23 \\
8.58 & 2.05 & 35.90 \\
2.77 & 0.94 & 8.15 \\
3.39 & 1.13 & 10.15 \\
0.86 & 0.29 & 2.58 \\
2.10 & 1.04 & 4.24 \\
1.14 & 1.05 & 1.23 \\
1.13 & 1.04 & 1.22 \\
1.12 & 1.05 & 1.18 \\
1.14 & 1.05 & 1.23 \\
1.19 & 1.10 & 1.28 \\
1.21 & 1.12 & 1.31 \\
1.11 & 0.91 & 1.34 \\
1.35 & 0.91 & 2.00 \\
1.99 & 1.40 & 2.84 \\
1.40 & 1.18 & 1.68 \\
1.11 & 0.79 & 1.54 \\
1.11 & 1.02 & 1.20 \\
2.80 & 1.47 & 5.35 \\
1.79 & 0.71 & 4.49 \\
& & \\
& & \\
1.21 & 1.14 & 1.28 \\
& Heterogeneity \\
$\mathrm{Q}=54.8 \mathrm{p}<0.001$ \\
\end{tabular}

Note: letters at end of authors' name shows different comparison groups within a single study.

Another action mechanism of stress involved in blood pressure increase could be indirect. Stress would be associated to risk factors such as obesity, smoking, alcohol abuse and physical inactivity and they would cause blood pressure increase. For example, a meta-analysis including 69 studies demonstrated that, despite the relatively small effects, physically active subjects had better cardiovascular recovery than inactive ones 39 .

In addition, the results of subgroup analysis show that individuals with higher blood pressure in the recovery period were twice as likely to have blood pressure increase when compared to those whose exposure was measured through reactivity. This finding suggests that cardiovascular measures of recovery can provide valuable information not captured in measures of reactivity and thus help predicting longitudinal changes in blood pressure 28 . A study found that individuals undergoing a stressful task had late recovery of blood pressure, which suggests recovery might be a helpful predictor of blood pressure increase 39 .
More pronounced effects were seen in studies with small losses and longer follow-up. In prospective studies there is greater concern with subject losses when they are associated to the study outcome or risk categories. The greater the loss, the greater the likelihood of bias 40 . Besides, in chronic exposures, such as stress, individuals have to be exposed for a time period long enough to set off the causal process 17 . Individuals aged between 46 and 64 years were about twice more likely to develop hypertension or blood pressure increase than young adults (Table 3 ).

This study has several limitations. The first is due to the heterogeneity of the studies selected. Measures of effect of highly heterogeneous studies have low validity 41 . In this study, heterogeneity was mostly due to differences in study populations, measures of exposure and outcome, losses and follow-up time. The effect of heterogeneity was partially overcome by the use of random effects models, subgroup analysis, a combination of effect by study and analysis of the impact of 
Random effects model, odds ratio and $95 \%$ confidence interval for the combined effect by study and the impact of the exclusion of each study.

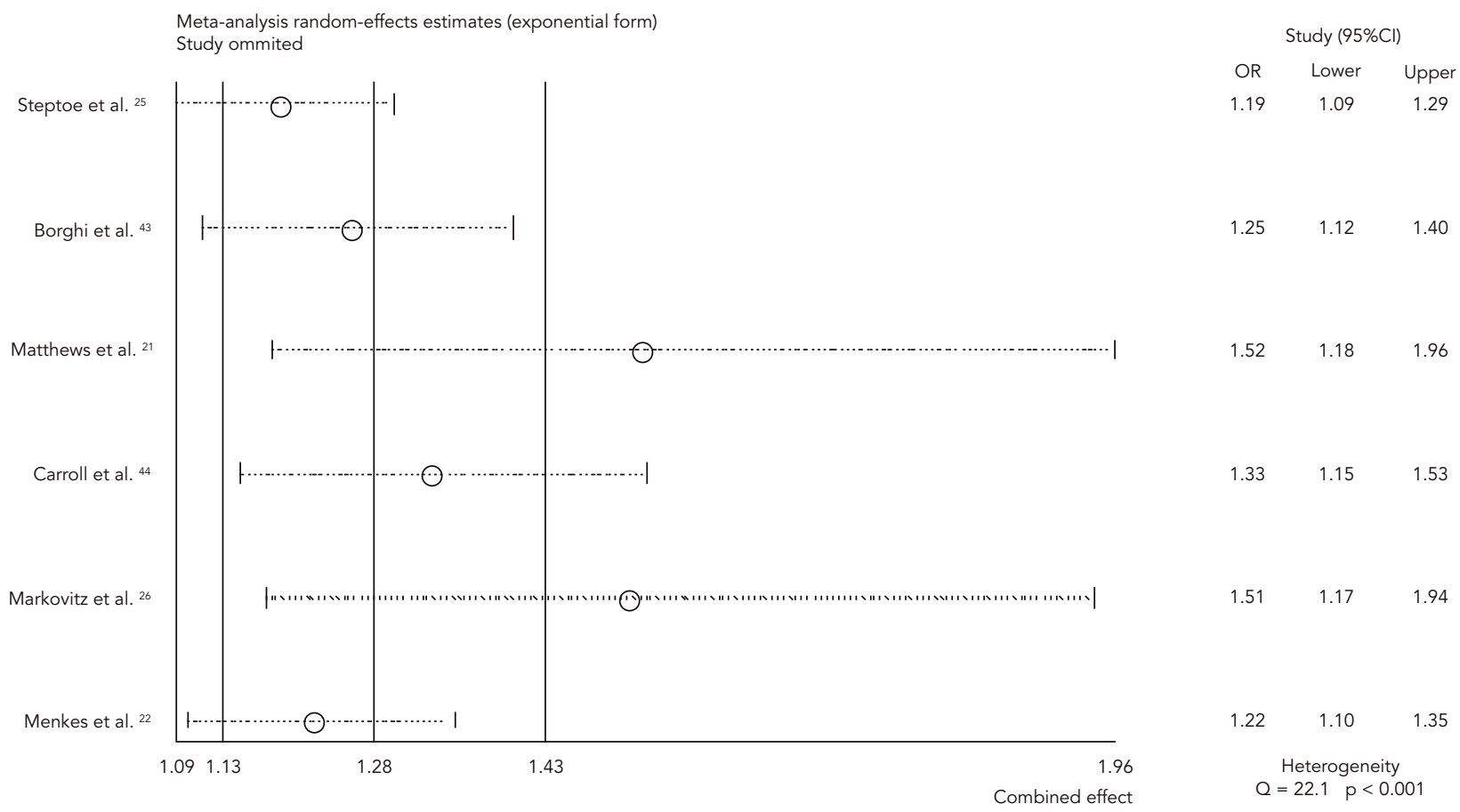

exclusion of each study on the final combined effect 41 . The second limitation is the detection of publication bias, which calls for a careful interpretation of findings. However, an evaluation comprising 48 systematic reviews of the Cochrane database demonstrated that, despite the fact that biases were seen in $50 \%$ of the studies, they significantly affected results in less than $10 \%$ of meta-analyses 42 . Third, although laboratory stress measurements potentially allow for greater control on the part of the investigator, stress tasks were applied on an acute basis and stress is assumed to occur chronically thus limiting test conclusions. The fourth limitation is related to the fact that the majority of studies included in the meta-analysis reported OR as measure of effect. When an outcome is commonly seen in a study population (as is the case of blood pressure increase), the OR might overestimate the effect of association 23 . However, further analyses showed that when OR were converted into relative risks, a relative risk of 1.17 (95\%CI: 1.10-1.25) was found for the combined effect. There seems to remain an effect of stress on blood pressure increase.
In conclusion, although the magnitude of effect was relatively small, results point to the relevance of control of psychological stress for the non-therapeutic management of high blood pressure. Further research investigating the role of stress in hypertension pathogenesis should be conducted. 
Table 3

Combined effect of psychological stress on the increase of the blood pressure in sub-groups of cohorts according to participants and study design.

\begin{tabular}{|c|c|c|c|c|c|}
\hline Variables & $\begin{array}{l}\text { Number of } \\
\text { combined }\end{array}$ & $\begin{array}{l}\text { Size of the } \\
\text { sample }\end{array}$ & OR $(95 \% \mathrm{Cl})$ * & $\mathrm{p}$-value & Heterogeneity \\
\hline \multicolumn{6}{|l|}{ Age (years) } \\
\hline $18-45$ & 12 & 30,946 & $1.18(1.12-1.24)$ & $<0.001$ & $p=0.002$ \\
\hline $46-64$ & 9 & 2,018 & $2.12(1.51-2.97)$ & $<0.001$ & $p=0.113$ \\
\hline $18-64$ & 2 & 1,592 & $1.15(0.97-1.37)$ & 0.118 & $p=0.371$ \\
\hline \multicolumn{6}{|l|}{ Sex } \\
\hline Men & 6 & 5,867 & $1.51(1.20-1.90)$ & $<0.001$ & $p=0.015$ \\
\hline Women & 2 & 3,526 & $1.11(1.02-1.19)$ & 0.01 & $p=1.0$ \\
\hline Men/Women & 15 & 25,163 & $1.18(1.11-1.25)$ & $<0.001$ & $p=0.006$ \\
\hline \multicolumn{6}{|l|}{ Loss (\%) } \\
\hline $0-10$ & 9 & 1,742 & $2.16(1.56-4.66)$ & $<0.001$ & $p=0.118$ \\
\hline $11-20$ & 7 & 13,891 & $1.17(1.12-1.22)$ & $<0.001$ & $p=0.116$ \\
\hline 21 or more & 7 & 18,923 & $1.18(1.10-1.26)$ & $<0.001$ & $p=0.009$ \\
\hline \multicolumn{6}{|l|}{ Years of follow-up } \\
\hline $0-10$ & 14 & 9,904 & $1.44(1.20-1.73)$ & $<0.001$ & $p<0.001$ \\
\hline $11-20$ & 7 & 23,491 & $1.15(1.12-1.18)$ & $<0.001$ & $p=0.393$ \\
\hline 21 or more & 2 & 1,161 & $2.41(1.42-4.10)$ & $<0.001$ & $p=0.433$ \\
\hline \multicolumn{6}{|l|}{ Test } \\
\hline Combined & 8 & 1,672 & $2.17(1.51-3.12)$ & $<0.001$ & $p=0.076$ \\
\hline Arithmetic & 3 & 1,662 & $1.19(1.01-1.41)$ & 0.044 & $p=0.181$ \\
\hline Videogame & 6 & 14,862 & $1.21(1.10-1.32)$ & $<0.001$ & $p=0.003$ \\
\hline Cold pressor & 4 & 8,177 & $1.19(1.04-1.36)$ & 0.01 & $p=0.041$ \\
\hline Star tracing & 2 & 8,183 & $1.16(1.09-1.22)$ & $<0.001$ & $p=0.377$ \\
\hline \multicolumn{6}{|l|}{ Exposure } \\
\hline Reactivity & 15 & 32,884 & $1.18(1.12-1.24)$ & $<0.001$ & $p=0.007$ \\
\hline Recovery & 8 & 1,672 & $2.17(1.51-3.12)$ & $<0.001$ & $p=0.076$ \\
\hline \multicolumn{6}{|l|}{ Outcome } \\
\hline HTN & 11 & 26,244 & $1.15(1.12-1.19)$ & $<0.001$ & $p=0.124$ \\
\hline $\mathrm{SBP} / \mathrm{DBP}$ increase $\geq 3.5 \mathrm{mmHg}$ & 12 & 8,312 & $1.59(1.25-2.03)$ & $<0.001$ & $p<0.001$ \\
\hline \multicolumn{6}{|l|}{ Multivariable analysis } \\
\hline Yes & 19 & 27,916 & $1.19(1.12-1.27)$ & $<0.001$ & $p=0.002$ \\
\hline No & 4 & 6,640 & $1.32(1.05-1.66)$ & $<0.001$ & $p=0.002$ \\
\hline
\end{tabular}

HTN: hypertension; SBP: systolic blood pressure; DBP: dyastolic blood pressure.

* Fixed effects models are used when the heterogeneity test was statistically non-significant $(p \geq 0.05)$ and random effects models when the test was statistically significant. 


\section{Resumo}

Estudos sugerem que a exposição crônica ao estresse tenha influência no aumento dos níveis pressóricos. Foi realizada uma revisão sistemática seguida de metanálise com o objetivo de avaliar o efeito do estresse psicológico no aumento da pressão arterial. As principais bases de dados utilizadas foram Ingenta, Psycinfo, PubMed, Scopus e Web of Science. Os critérios de inclusão foram: publicado entre janeiro de 1970 e dezembro de 2006, delineamento de coorte prospectiva, adultos, estresse psicológicolemocional como exposição principal, hipertensão arterial ou aumento na pressão arterial $\geq 3,5 \mathrm{mmHg}$ como desfecho. A busca resultou em 2.043 artigos, sendo 110 coortes. Desses, seis eram elegíveis, os quais geraram 23 grupos de comparação e 34.556 sujeitos. A mediana do tempo de seguimento e do percentual de perdas foi 11,5 anos e 21\%. Indivíduos com maior reação a tarefas estressoras possuíam $21 \%$ mais chances de apresentar aumento na pressão arterial quando comparados com aqueles com menor reação $(O R=1,21$; IC95\%: 1,14-1,28; $p<0,001)$. Embora com magnitude de efeito relativamente modesta, os resultados sugerem a importância do controle do estresse psicológico no tratamento não medicamentoso da hipertensão arterial sistêmica.

Pressão Arterial; Hipertensão; Estresse Psicológico

\section{References}

1. World Health Organization. The World Health Report 2002: reducing risks, promoting healthy life. Geneva: World Health Organization; 2002.

2. Chobanian AV, Bakris GL, Black HR, Cushman WC, Green LA, Izzo Jr. JL, et al. The Seventh Report of the Joint National Committee on Prevention, Detection, Evaluation, and Treatment of High Blood Pressure: the JNC 7 report. JAMA 2003; 289:2560-72.

3. Kearney PM, Whelton M, Reynolds K, Muntner P, Whelton PK, He J. Global burden of hypertension: analysis of worldwide data. Lancet 2005; 365 : 217-23.

4. Kawachi I, Malcolm LA. The cost-effectiveness of treating mild-to-moderate hypertension: a reappraisal. J Hypertens 1991; 9:199-208.

5. Linden W, Moseley JV. The efficacy of behavioral treatments for hypertension. Appl Psychophysiol Biofeedback 2006; 31:51-63.

6. Khan NA, Hemmelgarn B, Herman RJ, Rabkin SW, McAlister FA, Bell CM, et al. The 2008 Canadian Hypertension Education Program recommendations for the management of hypertension: part 2 - therapy. Can J Cardiol 2008; 24:465-75.

7. McEwen BS. Physiology and neurobiology of stress and adaptation: central role of the brain. Physiol Rev 2007; 87:873-904.

8. Stansfeld S, Marmot, editors. Stress and the heart: psychosocial pathways to coronary heart disease. London: BMJ Books; 2002.

\section{Contributors}

D. Gasperin initiated the study, conducted the systematic review and wrote the manuscript. G. Netuveli assisted in the study design. J. S. Dias-da-Costa helped in theoretical aspects. M. P. Pattussi supervised the study and data analysis. All authors reviewed the manuscript and interpreted results.

\section{Acknowledgments}

D. Gasperin was supported by a scholarship from the Universidade do Vale do Rio dos Sinos (UNISINOS; process no. 03/03013-4). Thanks go to Dr. Juraci A. Cesar for valuable comments on the project and manuscript.
9. Yan LL, Liu K, Matthews KA, Daviglus ML, Ferguson TF, Kiefe CI. Psychosocial factors and risk of hypertension: the Coronary Artery Risk Development in Young Adults (CARDIA) study. JAMA 2003; 290:2138-48.

10. Steptoe A, Brydon L, Kunz-Ebrecht S. Changes in financial strain over three years, ambulatory blood pressure, and cortisol responses to awakening. Psychosom Med 2005; 67:281-7.

11. Rosengren A, Hawken S, Ounpuu S, Sliwa K, Zubaid M, Almahmeed WA, et al. Association of psychosocial risk factors with risk of acute myocardial infarction in 11119 cases and 13648 controls from 52 countries (the INTERHEART study): case-control study. Lancet 2004; 364:953-62.

12. Maxwell VR, Schneider RH, Ndich SI, Gaylord-King C, Salerno JW, Anderson JW. Stress reduction programs in patients with elevated blood pressure: a systematic review and metanalysis. Curr Hypertens Rep 2007; 9:520-8.

13. Centre for Reviews and Dissemination. Undertaking systematic reviews for research on effectiveness. New York: University of York; 2001.

14. Green S, Higgins JPT. Cochrane handbook for systematic reviews of interventions 4.2.6. Chichester: John Wiley and Sons; 2006.

15. Bartrop RW, Luckhurst E, Lazarus L, Kiloh LG, Penny R. Depressed lymphocyte function after bereavement. Lancet 1977; 1:834-6. 
16. Dorian B, Garfinkel P, Brown G, Shore A, Gladman D, Keystone E. Aberrations in lymphocyte subpopulations and function during psychological stress. Clin Exp Immunol 1982; 50:132-8.

17. Rothman KJ, Greenland S. Cohort studies. In: Rothman KJ, Greenland S, editors. Modern epidemiology. $2^{\text {nd }}$ Ed. Philadelphia: Lippincott Williams \&Wilkins; 1998. p. 79-92.

18. Treiber FA, Kamarck T, Schneiderman N, Sheffield D, Kapuku G, Taylor T. Cardiovascular reactivity and development of preclinical and clinical disease states. Psychosom Med 2003; 65:46-62.

19. Rutledge T, Linden W, Paul D. Cardiovascular recovery from acute laboratory stress: reliability and concurrent validity. Psychosom Med 2000; 62:648-54.

20. National Institute for Health and Clinical Excellence. The guideline manual. Appendix D methodology checklist: cohort studies. London: National Institute for Health and Clinical Excellence; 2007.

21. Matthews KA, Katholi CR, McCreath H, Whooley MA, Williams DR, Zhu S, et al. Blood pressure reactivity to psychological stress predicts hypertension in the CARDIA study. Circulation 2004; 110:74-8.

22. Menkes MS, Matthews KA, Krantz DS, Lundberg U, Mead LA, Qaqish B, et al. Cardiovascular reactivity to the cold pressor test as a predictor of hypertension. Hypertension 1989; 14:524-30.

23. Zhang J, Yu KF. What's the relative risk? A method of correcting the odds ratio in cohort studies of common outcomes. JAMA 1998; 280:1690-1.

24. Sutton AJ, Duval SJ, Tweedie RL, Abrams KR, Jones DR. Empirical assessment of effect of publication bias on meta-analyses. BMJ 2000; 320:1574-7.

25. Steptoe A, Marmot M. Impaired cardiovascular recovery following stress predicts 3 -year increases in blood pressure. J Hypertens 2005; 23:529-36.

26. Markovitz JH, Raczynski JM, Wallace D, Chettur V, Chesney MA. Cardiovascular reactivity to video game predicts subsequent blood pressure increases in young men: the CARDIA study. Psychosom Med 1998; 60:186-91.

27. Carroll D, Ring C, Hunt K, Ford G, Macintyre S. Blood pressure reactions to stress and the prediction of future blood pressure: effects of sex, age, and socioeconomic position. Psychosom Med 2003; 65:1058-64.

28. Stewart JC, France CR. Cardiovascular recovery from stress predicts longitudinal changes in blood pressure. Biol Psychol 2001; 58:105-20.

29. Treiber FA, Musante L, Kapuku G, Davis C, Litaker $\mathrm{M}$, Davis H. Cardiovascular (CV) responsivity and recovery to acute stress and future $\mathrm{CV}$ functioning in youth with family histories of CV disease: a 4year longitudinal study. Int J Psychophysiol 2001; 41:65-74.

30. Schwartz AR, Gerin W, Davidson KW, Pickering TG, Brosschot JF, Thayer JF, et al. Toward a causal model of cardiovascular responses to stress and the development of cardiovascular disease. Psychosom Med 2003; 65:22-35.
31. Gibbons GH. Pathobiology of hypertension. In: Topol EJ, Califf RM, editors. Comprehensive cardiovascular medicine. Philadelphia: Lippincott Williams \& Wilkins; 1998. p. 2907-18.

32. Manuck SB. Cardiovascular reactivity in cardiovascular disease: "once more unto the breach". Int J Behav Med 1994; 1:4-31.

33. Mezzacappa ES, Kelsey RM, Katkin ES, Sloan RP. Vagal rebound and recovery from psychological stress. Psychosom Med 2001; 63:650-7.

34. Ghiadoni L, Donald AE, Cropley M, Mullen MJ Oakley G, Taylor M, et al. Mental stress induces transient endothelial dysfunction in humans. Circulation 2000; 102:2473-8.

35. Kop WJ, Krantz DS, Howell RH, Ferguson MA, Papademetriou V, Lu D, et al. Effects of mental stress on coronary epicardial vasomotion and flow velocity in coronary artery disease: relationship with hemodynamic stress responses. J Am Coll Cardiol 2001; 37:1359-66.

36. Lewthwaite J, Owen N, Coates A, Henderson B, Steptoe A. Circulating human heat shock protein 60 in the plasma of British civil servants: relationship to physiological and psychosocial stress. Circulation 2002; 106:196-201.

37. von Kanel R, Mills PJ, Fainman C, Dimsdale JE. Effects of psychological stress and psychiatric disorders on blood coagulation and fibrinolysis: a biobehavioral pathway to coronary artery disease? Psychosom Med 2001; 63:531-44.

38. Brunner E, Davey Smith G, Marmot M, Canner R, Beksinska M, O'Brien J. Childhood social circumstances and psychosocial and behavioural factors as determinants of plasma fibrinogen. Lancet 1996; 347:1008-13.

39. Schuler JL, O'Brien WH. Cardiovascular recovery from stress and hypertension risk factors: a metaanalytic review. Psychophysiology 1997; 34:649-59.

40. Altman DG. Designing research. In: Altman DG, editor. Practical statistics for medical research. London: Chapman \& Hall; 1991.p. 74-106.

41. Higgins JP, Thompson SG, Deeks JJ, Altman DG. Measuring inconsistency in meta-analyses. BMJ 2003; 327:557-60.

42. Sterne JA, Egger M, Smith GD. Systematic reviews in health care: Investigating and dealing with publication and other biases in meta-analysis. BMJ 2001; 323:101-5.

43. Borghi C, Veronesi M, Bacchelli S, Esposti DD, Cosentino E, Ambrosioni E. Serum cholesterol levels, blood pressure response to stress and incidence of stable hypertension in young subjects with high normal blood pressure. J Hypertens 2004; 22:265-72.

44. Carroll D, Smith GD, Shipley MJ, Steptoe A, Brunner EJ, Marmot MG. Blood pressure reactions to acute psychological stress and future blood pressure status: a 10-year follow-up of men in the Whitehall II study. Psychosom Med 2001; 63:737-43.

Submitted on 07/May/2008

Final version resubmitted on $08 /$ Oct $/ 2008$

Approved on 14/Oct/2008 